\title{
CARLOS FUENTES Y LA IDENTIDAD DE MEXICO
}

\author{
POR
}

\section{FRANCISCO JAVIER ORDIZ VÁZQUEZ \\ Universidad de León}

La obra de Carlos Fuentes se halla recorrida por una serie de temas que, como el propio novelista ha reconocido, se repiten una y otra vez en cada uno de sus libros. "Uno viaja siempre a través de sus propias obsesiones", declaró en cierta ocasión el escritor mexicano, y esta afirmación se hace especialmente palpable en su narrativa, en la que desde distintos ángulos y con diferentes perspectivas se muestran, se debaten o se analizan problemas e inquietudes que apenas si han variado en esencia en sus casi cuarenta años de actividad literaria; entre todos ellos, las reflexiones sobre la identidad y la historia de México ocupan un lugar preeminente.

México comienza a plantearse como un problema y un enigma en la mente de Fuentes desde muy temprana edad. En sus primeros años de vida, el futuro novelista vive en diferentes lugares del continente americano obligado por las circunstancias que impone la profesión diplomática de su padre. Panamá, Washington, Santiago de Chile o Buenos Aires, van marcando hitos en la formación del joven y perfilando en él ese cosmopolitismo que será nota dominante de su personalidad. México es entonces una mera referencia lejana, distante, conocida tan sólo a través de lecturas o de episódicos contactos veraniegos. Pero un hecho decisivo ocurrido en 1938, la nacionalización del petróleo mexicano, cambia radicalmente la situación: Carlos, que entonces vivía en Washington, se convierte de la noche a la mañana en blanco de las burlas e insultos de los que hasta entonces habían sido sus compañeros de juego; así lo expresa el novelista recordando estos momentos:

Instantly, I became a pariah in my school. Cold shoulders, aggressive stares, epithets and sometimes blows. Children know how to be cruel ${ }^{1}$.

El niño toma conciencia de su carácter distintivo, de su pertenencia a un país, a una lengua y a una tradición:

\footnotetext{
1 "Carlos Fuentes: The Discovery of Mexico". Granta 22 (Cambridge, Autumn 1987), 224.
} 
I discovered that my father's country was real. And that I belonged to it. Mexico was my identity yet I myself lacked an identity ${ }^{2}$.

México se convierte desde entonces en una realidad obsesiva para Fuentes, circunstancia que contrasta en apariencia con el voluntario alejamiento físico que ha mantenido a lo largo de su vida y que le ha acarreado un sinfín de críticas. Caso significativo fue en su momento el del uruguayo Mario Benedetti quien, a raiz de la oposición de numerosos y destacados intelectuales al encarcelamiento del poeta cubano Padilla, censuró duramente a varios de sus colegas que, a su juicio, se permitían pontificar y dictar su criterio desde el otro lado del Océano ${ }^{3}$. Los dardos se dirigian entre otros hacia Fuentes, quien en reiteradas ocasiones ha intentado justificar su autoexilio:

Para mí es indispensable estar fuera de México por razones casi de higiene mental. Es un país muy enfermo en sus capas intelectuales. La capacidad de resentimiento y de autodestrucción de la gente es muy grande (...). Necesito ver el país de lejos. Hay gente que necesita estar muy cerca, como Rulfo. Yo no. Como Gogol veía a Rusia, así veo yo a Méxicot.

Al margen de esta relación personal apasionada y aparentemente contradictoria, la cultura, los mitos, la historia y la realidad actual de México son objeto permanente de análisis y debate en las obras de Fuentes ya desde sus inicios como novelista, claramente marcados por las pautas teóricas del debate ideológico sobre la identidad del mexicano que en los años 40 y 50 se encontraba en el primer plano de la actividad intelectual.

\section{EL MEXICANO A DEBATE}

La corriente de introspección y análisis de la realidad profunda de México y sus habitantes tiene su fecha de arranque en 1934 con la publicación de $E l$ perfil del hombre y la cultura en México. Su autor, Samuel Ramos, partía de un planteamiento basado en las teorías psicoanalíticas de Adler y consideraba que para llegar a conocer al mexicano era preciso un análisis completo y detenido de las distintas etapas y estratos que habían ido conformando su subconsciente. Se trataba en realidad de la aplicación al terreno histórico del concepto freudiano de la abreacción, consistente en la revisión de las fases de infancia y adolescencia del paciente como terapia para solucionar los problemas psíquicos de la madurez. Ramos encontraba en la violencia original de la conquista el trauma no superado que pesaba aún como una dura losa sobre la personalidad profunda

\footnotetext{
${ }^{2}$ Fuentes, 224.

${ }^{3}$ Mario Benedetti, El escritor latinoamericano y la revolución posible, México: Nueva Imagen,1974.

4 José María Marco, "Profecías y exorcismos",Quimera 68 (Madrid, 1987), 35.
} 
y colectiva del mexicano, y cifraba en el periodo independentista el nacimiento de ese complejo de inferioridad que durante mucho tiempo se tuvo como tópico del carácter del país. Peroal margen de interpretaciones concretas, la perspectiva de análisis que proponía Ramos suponía ya un claro rechazo tanto del indianismo romántico del pasado como del cerrado nacionalismo surgido tras la revolución: el mexicano no era un individuo aislado del mundo ni diferente del hombre de otras latitudes; se trataba de un ser humano como los demás, aunque sometido a unas circunstancias que moldeaban unas notas de carácter particulares; el alma nacional debra analizarse por tanto en el contexto de la universalidad de la especie.

El impacto de las guerras española y europea supone un reforzamiento de las teorías de Ramos. El desmoronamiento del mito de la vida civilizada del europeo, favorece el desarrollo de un relativismo cultural que rompe con el férreo etnocentrismo de Occidente. En este contexto, la cultura mexicana ya no será considerada excéntrica ni periférica, sino simplemente diferente. Alfonso Reyes, amigo y maestro de Carlos Fuentes, será uno de los intelectuales que con mayor claridad y erudición dé cuerpo teórico a estos conceptos.

El debate prosigue hasta la fecha crucial de 1950, momento en que Octavio Paz en su Laberinto de la soledad retoma y profundiza los aportes más significativos de la tradición anterior de auto-análisis. Paz parte de un criterio básicamente idéntico al que planteaba Ramos: la necesidad de llevar a cabo un amplio repaso histórico con el fin de poner al descubierto los "traumas" del país y buscarles soluciones. Este trayecto a través de la historia de México se inicia en el momento de la conquista, que el poeta-ensayista interpreta como el acto de violación perpetrado por el "macho" —el conquistador_sobre la mujer india; el mexicano de hoy es el resultado de una violencia original producida por el sometimien to forzado a una cultura ajena; es un hijo de la Malinche, de la madre violada, y por ello reniega de sus orígenes:

El mexicano no quiere ser ni indio ni español. Tampoco quiere descender de ellos. Los niega. Y no se afirma en tanto que mestizo, sino como abstraccion: es un hombre, se vuelve hijo de la nada. El empieza en sí mismos.

Ese acto inicial se ha venido perpetuando bajo distintas máscaras a lo largo de los ciclos repetidos de la historia mexicana y encuentra su símbolo y expresión en el verbo chingar - "santo y seña de México"-que resume esa idea de "hacer violencia sobre otro" y fundamenta la dialéctica que se establece entre el machochingón-dominador y el chingado-oprimido.

${ }^{5}$ Octavio Paz, El laberinto de la soledad (México: FCE, 1950), 78-79. 


\section{LOS PRIMEROS RELATOS DE FUENTES: MÉXICO COMO OBSESION.}

Las ideas de Octavio Paz se dejan sentir con fuerza en la generación de escritores mexicanos que comienza su actividad en la década de los cincuenta. Carlos Fuentes no es una excepción, y sus obras La región más transparente (1958) y La muerte de Artemio Cruz (1962) se hallan recorridas en su práctica totalidad por las tesis de quien siempre consideró como uno de sus principales maestros. De esta forma, en la primera de las novelas mencionadas se debaten las posturas encontradas de los partidarios del universalismo del mexicano y aquéllos aún aferrados a ideas estrechamente nacionalistas quienes, en muchos casos, veían en la cultura indígena lo más auténtico y representativo de la nación. El protagonista principal, Ixca Cienfuegos, y sobre todo su madre, Teódula Moctezuma, son los portavoces de un proyecto nostálgico que intenta propiciar un ambiguo y poco definido retorno al pasado. La réplica les viene de Manuel Zamacona quien, en la línea de Octavio Paz, sostiene que México es una nación mestiza cuyos habitantes aún no han superado el trauma de considerarse hijos de la Malinche:

Los mexicanos nunca saben quién es su padre; quieren conocer a su madre, defenderla, rescatarla (...). El padre consumó lo que nosotros nunca podremos consumar: la conquista de la madre. Es el verdadero macho y lo resentimos ${ }^{6}$.

La violencia se convierte en el acontecimiento primordial, en el verdadero acto fundacional de México que, como tal, se reactualiza periódicamente en distintos rituales, como la muerte absurda e inútil de Manuel Zamacona en un bar de carretera ola consagración de la dialéctica de la chingada como sistema de relación interpersonal.

Los temas que sobre la identidad de México se plantean en esta novela vuelven a hacer su aparición en La muerte de Artemio Cruz. El personaje central, postrado en su lecho de muerte, recuerda los doce momentos más significativos de su vida, que se convierten a su vez en un paradigma de la historia del país. Cruz es el símbolo de un proceso histórico fatalmente marcado por el pecado original de la chingada que ha dejado en la cuneta ideales y utopías; una situación que resume perfectamente Gamaliel Bernal, personaje representativo de la vieja oligarquía porfirista, a quien Artemio arrebata sus posesiones y su antiguo poder y privilegios:

Artemio Cruz. Así se llamaba,entonces, el nuevo mundo surgido de la guerra civil; asi se llamaban quienes llegaban a sustituirlo. (...) Desventurado país que a cada generación tiene que destruir a los antiguos poseedores y sustituirlos por nuevos amos, $\tan$ rapaces y ambiciosos como los anteriores?.

\footnotetext{
6 Carlos Fuentes, La región más transparente (Madrid: Cátedra, 1982), 197.

${ }^{7}$ Carlos Fuentes, La muerte de Artemio Cruz (México: Fondo de Cultura Económica, 1962), 50 .
} 
La solución que propone Fuentes pasa necesariamente por asumir las lecciones de la Historia y acabar de una vez para siempre con el estigma de la chingada:

Matémosla: matemos esa palabra que nos separa, nos petrifica,nos pudre con su doble veneno de ídolo y cruz: que no sea nuestra respuesta ni nuestra fatalidad ${ }^{8}$.

México y su circunstancia ocupan también lugar destacado en Las buenas conciencias, obra intermedia en el tiempo entre las dos anteriormente mencionadas (aparece en 1959), aunque el tema es tratado en un tono mucho menos especulativo y simbólico que en las novelas anteriores. Fuentes intenta rendir un homenaje a la narrativa de corte balzaciano, y en la construcción de este relato sigue al pie de la letra los parámetros de la novela tradicional, lo cual encorseta en exceso la exuberancia verbal y el torrente de ideas que fluían por las páginas de La región más transparente. La trama de Las buenas conciencias reproduce el esquema del Bildungsroman, y a través de la perspectiva del adolescente Jaime Ceballos, el narrador ofrece una visión muy crítica de la burguesía tradicional mexicana, localizada en este caso concreto en la ciudad de Guanajuato. Es, sin duda, la novela más floja de Fuentes, quien en reiteradas ocasiones se ha mostrado arrepentido de su publicación.

Poco después de la aparición de La muerte de Artemio Cruz ve la luz la novelita Aura, donde el autor profundiza en el concepto del tiempo detenido, que ya había tratado parcialmente en su cuento "Tlactocaltzine, del jardín de Flandes" incluido en su volumen de juventud Los días enmascarados (1954). Apoyado en una densa simbología cuyas claves, sin embargo, son fácilmente reconocibles, Fuentes muestra la evidencia de un país en el que el tiempo no transcurre y donde permanecen vivos y en contacto todos los momentos de su historia; éste es el sentido que adquiere el descubrimiento de la identidad del protagonista, Felipe Montero, quien se asimila a la personalidad del fallecido general Llorente, miembro de ejército del emperador Maximiliano.

\section{MEXICANISMO Y UNIVERSALISMO}

Los vehementes y apasionados planteamientos sobre México que aparecen en las primeras novelas de Carlos Fuentes se reducen y atemperan considerablemente en intensidad y frecuencia a partir del volumen de cuentos Cantar de ciegos. El autor abandona los aspectos y ambientes quizás excesivamente localistas de sus obras anteriores y tiende hacia un tratamiento mucho más amplio y genérico de temas y personajes. En esta transformación influyen de forma notable los años de residencia del escritor en Francia, donde se pone en contacto con las distintas tendencias de pensamiento que bullían en

' Fuentes, 146. 
el ambiente cultural europeo del momento. Entre todas ellas resulta de gran interés destacar la importancia que adquieren las teorías estructuralistas en general, y en particular las ideas del antropólogo Lévi-Strauss, en esta etapa de la producción del mexicano.

Las tesis de Lévi-Strauss presentaban ciertos puntos de confluencia - más aparentes que reales, ciertamente-con los planteamientos psicoanalíticos de Jung en lo concerniente a la homogeneidad esencial de las culturas humanas. Ambos concebran la existencia de un pensamiento mítico - en expresión de Ernst Cassirer - común a toda la humanidad, que se manifestaba bajo la forma de arquetipos (Jung) que conformaban la estructura profunda (Lévi-Strauss) de la mente. Estas tesis suponían una clara contradicción de las teorías etnocéntricas y entroncaban directamente con aspectos fundamentales de la filosofía de lo mexicano. En más de una ocasión Fuentes ha manifestado su conocimiento de los trabajos de Jung y su adhesión a las teorías levistraussianas; así se expresa en una entrevista con Gladys Feijó:

Yo creo que hay un substrato mítico que es común a todos los pueblos del mundo. Lévi-Strauss dijo alguna vez que los mitos viajan, y en efecto, podemos encontrar mitos que se repiten a lo largo de la historia de la humanidad, en todas las geografias imaginables ${ }^{9}$.

A partir de este momento, la narrativa de Carlos Fuentes tenderá en buena medida a la búsqueda de ese "substrato mítico común", tendencia que se prolongará hasta 1980. Las novelas de esta época se caracterizan básicamente por su densidad simbólica y un fuerte intelectualismo que se conjuga con una construcción formal totalmente alejada de los moldes realistas; todo ello se traduce en ocasiones en un hermetismo prácticamente impenetrable que convierte a Fuentes en un escritor dificil cuando no elitista. Esta circunstancia se advierte en Cambio de piel (1967), donde el novelista percibe en la historia común de Occidente la perpetuación de la violencia del hombre sobre el hombre, algo connatural a la especie humana y ya no sólo privativo de México. La acción de la novela encuentra su punto culminante en el ritual de renovación que se manifiesta en el juicio que el tiempo nuevo (los Monjes) dicta sobre el viejo (los viajeros, con excepción de Isabel). El asesinato de Franz, antiguo colaborador de los nazis, simboliza de forma particular el castigo, la muerte y la culminación de un mundo pasado y detestable; así nos lo hace saber el narrador:

Es lo viejo. Debe morir. El ciclo ha terminado y lo nuevo debe nacer sobre los despojos de lo viejo ${ }^{10}$.

- Gladys Feijoo, "Entrevista a Carlos Fuentes". Románica, XIV, 1977, 72.

${ }^{10}$ Carlos Fuentes, Cambio de piel (Barcelona: Seix-Barral, 1974), 492. 
La muerte de este personaje se convierte por tanto en un auténtico sacrificio propiciatorio de la continuidad y la renovación de la vida; un cambio de ciclo o de piel que, sin embargo, no se presenta como algo idnlico; por el contrario, la filosofia esencialmente pesimista del autor parece apuntar hacia un final sin esperanza, en el que los revolucionarios acaban cayendo en los mismos crímenes y errores que intentaron erradicar. "No sé si los monjes están infectados de lo mismo que condenan", afirma el narrador, en una idea que Fuentes confirma a Emir Rodríguez Monegal:

Tanto la violencia de los españoles en Cholula como la posterior violencia de los beatniks en la pirámide, como la violencia que quemó a los judíos en Estrasburgo, o la violencia nazi, son la misma violencia ${ }^{11}$.

La visión crítica de Fuentes se extiende a una ácida censura de la sociedad de consumo, del neo-imperialismo norteamericano y de los mitos modernos que sustentan los centros de poder mundiales o locales para controlar a la población. México es uno de los lugares del mundo que sufren de forma más evidente esta situación: sus habitantes viven entregados al culto de la diosa Pepsicóatl, mientras permanecen ciegos a su verdadera realidad. Como resume de forma irónica el narrador de la novela:

Compran latas en Minimex para que pronto caigan bombas en Pekín y el mundo se salve para la libertad y los jabones Palmolive, huyen de las rotiserias con el cadáver de un pollo frito bajo el brazo para que los infantes de marina crucen pronto el río Bravo del Norte y el Bío-Bío del Sur (...). Salen de Sears-Roebuck con una aspiradora nuevecita para que el mundo pronto sea un campo de fósforos,suben a sus Chryslers y Plymouth y Dodges para que cuanto antes el mundo esté en orden, en paz, tranquilo, decente, sin amarillos, negros, sin colores $^{12}$.

México y el mexicano ante su universalidad. Esta premisa que guía la narrativa más significativa de Carlos Fuentes se refleja particularmente en Zona sagrada (1967), novela en la que se advierte con claridad la influencia de las teorías de Lévi-Strauss. En principio, la atención primordial de la temática parece centrarse en la pasión desmedida y completamente enfermiza del joven Guillermo - Mito- hacia su madre, la actriz mexicana Claudia Nervo. El desequilibrio psíquico del personaje, que sólo piensa en evadirse de un mundo que considera hostil y sueña con fantasías de retorno a un protector seno materno, se refleja también en el paralelismo que establece en su imaginación entre su propia historia y la del héroe clásico Ulises, cuyas referencias mitológicas

\footnotetext{
${ }^{11}$ Emir Rodriguez Monegal, "Carlos Fuentes", en Giacoman, Helmy F. (ed.), Homenaje a Carlos Fuentes (NuevaYork: Las Américas Publishing Co., 1972), 41.

${ }^{12}$ Cambio de piel, 465.
} 
se confunden y entremezclan con otras pertenecientes a culturas diversas, especialmente la azteca. Lo que pretende Fuentes en realidad es mostrar cómo narraciones y personajes mitológicos de mundos distantes encuentran puntos de confluencia que ponen al descubierto su identidad de base. El mito es universal, igual que las formas de pensamiento profundas del ser humano, y desde esta perspectiva resulta absurdo analizar al mexicano como un individuo aislado del resto del mundo. Como le explica Carlos Fuentes a Luis Harss, ya ha pasado el momento de plantarse delante de un espejo para preguntarse qué significa ser mexicano; a hora, señala el novelista, "el problema es ser hombre" ${ }^{\text {"13 }}$.

Esta línea temática prosigue en Terra nostra (1975), la novela más extensa de Fuentes, y donde el mexicano da rienda suelta a todos sus problemas y obsesiones. A lo largo de la enmarañada trama del relato, el novelista viaja a través de tiempos y lugares diferentes - la antigua Roma, la España de Felipe II, el mundo oriental y judío, la América prehispánica - con el fin de rastrear los diferentes sustratos culturales que han ido conformando la personalidad de esa terra nostra compartida por la comunidad hispanohablante, y en particular por México y España. Fuentes tiende de nuevo a poner de relieve los puntos comunes tanto en lo referente a los procesos históricos como a los sistemas mitológicos de los diferentes lugares por los que transcurre la acción de la novela. En el primero de los casos, la conclusión es idéntica a la que se ofrecía en Cambio de piel: el mundo de hoy vive sumido en el engaño del orden y el progreso, cuando en realidad lo que demuestra la Historia es la perdurabilidad de una situación dominada por la violencia que adquiere distintas máscaras dependiendo del lugar o el momento, y que se manifiesta tanto en los corruptos gobiernos imperiales de la antigua Roma como en la actual administración norteamericana, y de igual manera en los exterminios de judios en la Edad Media como en la represión política actual. México y su devenir no son más que un capítulo integrado en el contexto de la historia común de una Humanidad que no parece tener más solución que un holocausto como el que describe el final del relato. Terra nostra también se relaciona con Zona sagrada en el juego mitológico que entremezcla, e identifica temas y personajes pertenecientes a culturas diversas; el interrogante que plantea el personaje Ludovico al monarca Felipe II resume con claridad la idea de fondo:

... ¿por qué han soñado, pensado o vivido lo mismo todos los hombres en el albor de su historia, venciendo todas las distancias, como si todos, Felipe, todos, nos hubiésemos conocido antes de nacer en un lugar de encuentros comunes y luego, en la tierra,s6́lo nos hubiesen separado los azares de espacios alejados, tiempos diferentes, ignoradas ignorancias? ${ }^{14}$.

Las distintas perspectivas de análisis de la personalidad hispanoamericana se confrontan en Una familia lejana (1980). Víctor Heredia, cubano de origen

\footnotetext{
${ }^{13}$ Luis Harss, Los nuestros (Buenos Aires: Sudamericana, 1977), 314.

14 Carlos Fuentes, Terra Nostra (Barcelona: Seix-Barral, 1975), 600.
} 
afincado en París, es el representante del proyecto europeísta que reniega de lo propio y vuelve sus ojos hacia el mito de la civilización occidental y su centro privilegiado: la capital francesa. Frente a él, Hugo Heredia pretende encontrar la auténtica identidad del americano en el pasado, en el "mensaje de las piedras". Se trata de un viejo planteamiento en el que Fuentes ahora se involucra personalmente al comparecer como un personaje más de la obra. El novelista se describe ante el lector como un hombre de educación cosmopolita, desarraigado físicamente de su pars, que siente en su propia carne el dolor de las heridas aún no cicatrizadas del hombre americano y que ha encontrado en Europa, y más concretamente en Paris, su verdadero equilibrio espiritual; él mismo es también Heredia, es decir, parte activa de ese mundo dividido y desgajado y, como paradigma de la personalidad hispanoamericana, lleva a sus espaldas un fantasma que le recuerda las posibilidades truncadas, inconclusas, los caminos no tomados que - en un tema que aparecía ya en La muerte de Artemio Cruz-pudieron haber hecho de él otra persona. América está plagada de "Heredias" que, a pesar de sus lazos de sangre, se dividen en proyectos distintos; en el continente se perpetúa la lucha entre hermanos, y el estigma de Caín determina fatalmente la Historia. La extraña fusión entre los jóvenes Víctor - el hijo del mexicano-y André-hijo del francés-puede interpretarse en esta línea como el deseo de una integración, de una unión necesaria para encarar el futuro. Pero al final todo permanece deliberadamente ambiguo: tras contemplar los misteriosos fetos que descansan en la piscina del RAC de París, símbolo de ese nuevo ser americano aún no nacido, Fuentes declara lacónicamente: "Nadie recuerda toda la historia".

\section{MEXICO, DE NUEVO AL FIN}

Con Agua quemada (1981) se produce el "retorno a casa" de Carlos Fuentes. Desaparece de su narrativa el tono altamente especulativo de anteriores trabajos, el relato regresa a cauces cercanos al molde tradicional y los temas vuelven a estar localizados casi con exclusividad en México. El propio autor es consciente de esta vuelta a sus orígenes como novelista, y así parece manifestarlo con tres significativos datos: el título, tomado de Octavio Paz, y las citas iniciales de este autor y de Alfonso Reyes, que remiten a sus dos grandes maestros de juventud, y la publicación de la obra en el Fondo de Cultura Económica, que desde La muerte de Artemio Cruz no había vuelto a editar ninguna novela del mexicano.

En su viaje por el México de los años 70 y 80 el escritor descubre que todos los problemas que veinte años atrás había dejado sobre el tapete no sólo no se han solucionado, sino que se han agravado de forma considerable. La ciudad ha crecido desmesuradamente hasta convertirse en una mole urbana anárquica, opresiva y violenta; las desigualdades sociales se han profundizado aún más, y ya es un hecho la implantación de un dominio norteamericano que impone sus 
modas, sus gustos y hasta su idioma. Además, si en La región más transparente hacían su aparición personajes que, como Ixca Cienfuegos o Manuel Zamacona, exponian planes de futuro - equivocados o no-que suponian una cierta dosis de idealismo, en los cuentos de Agua quemada nadie se erige en portavoz de una esperanza que, parece ser, ya no existe. El proyecto integrador de Zamacona se ha convertido en una utopía irrealizable, mientras que el nostálgico retorno al pasado de Ixca ya no cuenta en una sociedad que sólo vive para lo inmediato; asimismo, la fuerza de un Federico Robles o de un Artemio Cruz, condenables quizá por su actividad pública, pero de una indudable dimensión humana que los hacía tremendamente atractivos, se diluye en la mediocridad de un Vicente Vergara, que sólo vive de recuerdos de la épica revolucionaria, o de su hijo, enriquecido con el tráfico de drogas. Los personajes de Agua quemada malviven en un presente sin esperanza del que se han desterrado todo proyecto y toda visión de futuro; son ancianos, delincuentes o tarados, a quienes sólo les preocupa la supervivencia diaria. Ante esta situación los personajes hacen volar su imaginación hacia tiempos pasados que consideran más felices: Vicente Vergara sueña con el México vivo de la revolución, el niño Luisito con el antiguo esplendor de los palacios coloniales, mientras que Federico Silva añora la tranquilidad del México de los años cincuenta.

Si Agua quemada puede considerarse hasta cierto punto un apéndice o revisión de'La región más transparente, Gringo viejo (1985) es una vuelta a la temática de la revolución, que no era tratada directamente desde La muerte de Artemio Cruz. Pero la óptica ha cambiado notablemente: ya no se trata de la evaluación desengañada de los resultados de la revuelta, sino de la contemplación nostálgica de un importante evento que sirvió para despertar a México y que pudo haber transformado el rumbo de su historia. Por ello quizás, varios personajes de la novela mantienen aún la frescura y el idealismo de los primeros momentos de la campaña. Es el caso del general Arroyo, cuya muerte nos deja una vez más ante la evidencia de que en México no hay lugar para soñadores e idealistas, que perecen aplastados ante la eterna dinámica de la violencia.

El agrio retorno de Fuentes cobra una nueva dimensión en Cristóbal nonato (1987). El novelista, en un tono irónico y burlón, ofrece una surrealista visión de su pars en ese próximo futuro del año 1992: México se halla hundido en la bancarrota y se ha fragmentado en distintas repúblicas independientes; la ciudad, auténtica jungla humana, muere lentamente: la basura se enseñorea de sus calles y la lluvia ácida se ha convertido en una realidad cotidiana. La población sobrevive como puede en medio de una violencia a flor de piel que sólo requiere la ocasión propicia para manifestarse, como sucede en el grotesco episodio del ayatolá Matamoros Moreno, erigidoen auténtico mesías de la miseria. El narrador, niño nonato que refiere sus experiencias desde el seno materno, vive los días previos a su nacimiento obsesionado con la certeza de que que éste supondrá un olvido de esa especie de omnisciencia intrauterina de la que es poseedor, y con ello estará abocado a repetir los mismos errores que han 
marcado fatalmente la historia de su país. De nuevo, una visión desesperanzada de México y una reflexión sobre la necesidad de aprender las lecciones de la Historia.

En varios de los relatos que integran Constancia $y$ otras novelas para vírgenes (1989) se percibe también la visión totalmente negativa del presente de México y la añoranza por el pasado. Toño y Bernardo, protagonistas de La desdichada recuerdan una ciudad que "tenía color de mármol y volcán quemado y sonaba a campanadas de plata y olía a piña y cilantro ${ }^{n 15}$, en la que ahora sólo se respira un aire turbio. En la misma línea, Santiago Ferguson, de Gente de razón, lamenta "la destrucción de la ciudad más vieja del Nuevo Mundo" que languidece "bajo una capa de humo industrial"16. Una ciudad que sin embargo sigue siendo el paradigma de un país misterioso, inexplicable, cuando no absurdo ("México es Fellini instantáneo", afirma otro personaje del mismo relato), donde coexisten intactos distintos tiempos históricos, y una población indígena y rural, fuertemente apegada a sus costumbres ancestrales, convive con una élite acomodada que tiene a su disposición la más avanzada tecnología. El problema de México reside, una vez más, en una historia no asumida, y su misterio en la pervivencia de un pensamiento mítico-analógico que contrasta con el del civilizado hombre occidental.

Con La campaña (1990) Fuentes rinde tributo al género de la novela histórica, que en los últimos tiempos parece cobrar nuevo auge en la literatura hispanoamericana. La trama principal narra los románticos amores del argentino Baltasar Bustos por la chilena Ofelia Salamanca, que llevan al galán a recorrer toda Hispanoamérica en plena campaña independentista y entrar en contacto con los cabecillas más destacados. De nuevo en la obra se recoge la confrontación entre distintas visiones y proyectos para Hispanoamérica, concretados en este caso en una guerra de independencia que supuso la llegada al poder de una élite criolla que despreciaba a los indígenas y que intentó una imitación ilógica de los moldes europeos sin tener en cuenta la realidad del continente.

México e Hispanoamérica; su cultura y su historia jalonada de utopías y frustraciones, su identidad multirracial y la incertidumbre de su destino son, como se ha visto, temas debatidos hasta la saciedad en la obra narrativa de Carlos Fuentes. "México será un país maduro el día que haya una estatua de Hernán Cortés en el Paseo de la Reforma ${ }^{17}$, ha dicho el novelista en una frase que condensa claramente su pensamiento: los paises hispanohablantes sólo hallarán un futuro viable si asumen su pasado sin rechazos ni exclusiones y

\footnotetext{
${ }^{15}$ Carlos Fuentes, Constanciay otras novelas para virgenes (Madrid: Mondadori, 1989), 81.

${ }^{16}$ Fuentes, 283.

${ }^{17} \mathrm{M}^{\mathrm{9}}$ Victoria Reyzábal, "Mantener un lenguaje o sucumbir al silencio". En VVAA: Carlos

Fuentes (Barcelona: Anthropos-Ministerio de Cultura, 1988), 95.
} 
extraen de él las lecciones precisas para establecer un proyecto propio y personal; como apostilla de nuevo el escritor "debemos estar listos para recibir al pasado si queremos tener un presente y un porvenir ${ }^{n 18}$.

Con La campaña se completa hasta el momento la trayectoria narrativa de nuestro Premio Cervantes 1987. Pero Fuentes ya ha anunciado para los próximos años la aparición de nuevas novelas en las que, a juzgar por su título, México seguirá siendo preocupación obsesiva y recurrente.

\footnotetext{
${ }^{18}$ Carlos Fuentes, "Una perspectiva iberoamericana”. $A B C$ (Madrid, domingo 17 de junio de 1984), 56.
} 